$\operatorname{Ag} 8.3: 166$

3. E. S. IIBTHRY. COF P

\title{
THE CONNECTICUT
}

\section{AGRICULTURAL EXPERIMENT SIATION}

NEW HAVEN, CONN.

\section{BULLETIN 166, NOVEMBER, 1910.}

\section{THE MANAGEMENT OF TOBACCO SEED BEDS.}

\author{
By W. M. Hinson and E. H. Jenkins.
}

The Bulletins of this Station are mailed free to citizens of Connecticut who apply for them, and to others as far as the limited editions permit. 


\section{CONNECTICUT AGRICULTURAL EXPERIMENT SPATTION. \\ OFFIOFRS AND STAFF-}

\section{BOARD OF CONTROL.}

His Excellency, Frank B. WeEks, Ex officio, President.

Prof. H. W. Conn, Vice President....................Middletown.

E. H. Jenkins, Director and Treasurer................. New Haven.

George A. Hopson ...................................

Charles M. Jarvis............................... Berlin.

Frank H. StadtMueller $\ldots \ldots \ldots \ldots \ldots \ldots \ldots \ldots$. Elmwood.

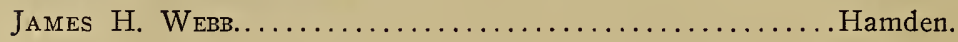

\section{STATION STAFF.}

Chemists.

Analytical Laboratory.

John Phillips Street, M.S., Chemist in Charge.
E. Monroe Bailey, M.S.
C. B. MORRISON, B.S.
R. B. RoE, A.B.
C. E. SHEPARD.

Laboratory for the Study of Proteids.

T. B. Osborne, Ph.D., Chemist in Charge. E. L. Ferry, Assistant.

Botanist, G. P. Clinton, S.D. Assistant, E. M. Stoddard.

Entomologist, W. E. Britton, Ph.D. Assistant, B. H. Walden.

Forester, Samuel N. Spring, M.F. Assistant, W. O. Filley.

Plant Breeding, H. K. HAYES, B.AGR.

Seed Testing, Miss M. H. JAGger.

Stenographers and Clerks. Miss V. E. Cole, Miss L. M. Brautlecht,

Miss E. B. Whittlesey, Miss Luva Friancis.

In Charge of Buildings and Grounds, William Veitch.

Laboratory Helper, Hugo Lange. Sampling Agent, V. L. Churchill. 


\title{
THE MANAGEMENT OF TOBACCO SEED BEDS.
}

\author{
By W. M. Hinson and E. H. Jenkins.
}

This bulletin is a part of the coöperative experimental work done jointly by the Bureau of Plant Industry of the United States Department of Agriculture, represented by Mr. Hinson, and by this Station.

The object of the seed bed is to get healthy stocky plants with compact roots ready to set in the field when the ground and air are warm enough for them to grow rapidly and without check. This bulletin aims to give what experiment and observation have taught regarding this matter.

The same beds may be used for years if properly handled, and this plan makes it worth while to build substantial wooden frames, to hold the cloth or sash and in some cases to lay steam or water pipes in the bed for heating in emergency. The dangers from the accumulation of weeds, the increase of fungi or "disease" in the soil, and the sprouting of tobacco seed possibly of a different variety sowed the previous year, are all obviated by the sterilization of the bed with steam, to be described later.

Fertilizers. Tobacco plants of the right size to set in the field carry very little plant food in them and can grow to the proper size for transplanting in a poor soil. But if they grow in either a poor or a dry soil, they have to spread their roots widely in it in order to get the food or water which they need. This delays their growth above ground, the spreading, straggling roots are damaged in transplanting and the plant, as a result, is checked in growth.

But in a well-fertilized bed the roots, finding all the plant food and water which they need close at hand, make a compact bunch of roots easy to pull with slight loss to the seedling plant. To secure this it is not necessary to use exceptionally large doses of fertilizer. 
The complete or partial failure of beds is oftener caused by too thick seeding and want of skill or care in watering and particularly in airing the beds than by over-fertilizing or underfertilizing the soil. If the plants do not grow as they ought, seek the cause in these things and in diseases which result from insufficient ventilation before dosing the bed with fertilizers.

Horse manure is an excellent dressing, for, aside from its fertilizing value, the vegetable matter in it makes the soil hold and carry water better than it could without it and feeds the bacteria which make nitrogenous manures available. If beds are steam-sterilized, the weed seeds, which are always present in manure, will give no trouble.

Usually it is best to prepare the beds and work in manure in the late fall, thus leaving less to be done in the rush of spring work. A thick cover of leaves on the bed prevents deep freezing and makes the beds workable somewhat earlier in the spring.

A moderate amount of chemical fertilizers should be put on in spring, worked in with the rake, and the bed cleaned of all trash and smoothed ready for seeding.

Object of Sterilizing the Beds. To this matter we wish to call special attention. The sterilization of beds used for forcing greenhouse crops has been practiced by successful growers for years. The results of our experiments in sterilizing tobacco beds have led some successful growers to adopt this practice, which has thus been abundantly tested and has proved to be practicable and profitable. The practice, which will be described in detail later, consists either in steaming the soil sufficiently to kill all seeds and microbes in it to the depth of two inches or more, or in treating the beds with formalin to largely accomplish the same thing. Beds which have been properly sterilized by steam will need no weeding, as only an occasional weed will show itself before the seedling tobacco plants are pulled. This saving of labor alone pays the cost of sterilizing when the apparatus for it is at hand. The root rot will also be killed and the tobacco thus saved from its attacks. Whether "calico" is lessened by the treatment has not been determined, although our observation this year, to which we refer later, suggested that this might be the case. 
It is a matter of common observation, both in greenhouses and in tobacco beds, that the plants in sterilized soil start quicker and grow faster than in untreated soil. This may be in part explained by the warming of the soil, partly by a possible solvent action of the steam or heated moisture on the plant food in the soil, but is no doubt in large part due to a change in the microbe life of the soil effected by the treatment, which may utterly destroy certain kinds of microbes, repress others and yet leave conditions favorable for the rapid growth later of those species which make available the nitrogen of the soil or otherwise favor the growth of the tobacco plant.

The root rot and some other fungous troubles appear to be completely destroyed by steam sterilization and largely by the formalin treatment.

Apparatus for Steam Sterilizing. There are required a portable steam boiler-six to eight horse power-which will maintain a pressure of from 75 to 100 pounds, and steam hose which will stand that pressure, with the necessary connections. The steaming apparatus found most convenient was devised by Mr. A. D. Shamel and is shown in the plate.

It is a pan six by ten feet square and six inches deep, made of I8-gauge galvanized iron and having a handle bar at each end. It is reinforced with strap iron to make it more rigid and is fitted with a nipple for the hose connection. The one in use at East Hartford cost $\$ 40.00$ and should last ten years.

If a sterilizing pan cannot be got readily, experience has shown that a tight wooden box of about the same measurement is equally effective and being a poor conductor of heat probably needs less steam to do the same work.

The Operation of Steam Sterilizing. The bed, having been fertilized, is raked smooth and made ready for sowing. The pan is inverted over one end of the bed and its edges pressed well into the soil. Steam is turned on and kept at a pressure of at least 70 pounds for thirty minutes. Some experimenters recommend an hour, but in our work this year thirty minutes was sufficient to kill all seeds.

The pan is then moved on, and it is recommended to cover the steamed soil with burlap to hold the heat as long as may be. 
Where the beds are many and long, much time can be saved by putting the boiler midway of the bed and using two sterilizers, one at each end of the bed. The steam is turned into the second when the first has been steamed for thirty minutes, and the pan remains there to hold the heat for twenty-five minutes and is then moved on.

To sterilize I80 square yards of seed beds this year at W. K. Ackley's in East Hartford cost the labor of two men for two days, $\$ 6.00$. No weeding was needed on these beds.

To weed 90 square yards of unsterilized beds till the seedlings were pulled, cost in labor \$12.00.

The beds were sterilized April IIth and I2th. Seed was sown on the I5th. The covers were taken off the beds May I5th and the seedlings were ready to set on June $2 \mathrm{~d}$, all of them healthy.

The plants on unsterilized and hand-watered beds were one week later.

As to the effect on prevalence of "calico," we do not yet attach great importance to our observations because of the freaky way in which this trouble appears. Part of the field was set with plants from the sterilized bed and part from an adjoining one which was not sterilized. We counted all the plants in two rows on both parts and also the number of "mongrels" or "calico" plants. Only $2^{1 / 2}$ per cent. of the plants from sterilized beds showed the trouble, but from the unsterilized bed 30 per cent. But on a neighbor's field, where the same experiment was made, the difference was not great, though still quite evidently in favor of the plants from sterilized soil.

The subject of "calico" is further discussed in the last paragraph of this bulletin.

Sterilization with Formalin or Formaldehyde. Steam sterilization is the more convenient where a boiler is near at hand and effective in killing weed seeds, but for small beds and places where the other apparatus cannot be got, the formalin treatment can be substituted. It is best applied in the fall and when the soil is comparatively dry. The following method was successfully used by Dr. Clinton of this Station in 1907:

A solution of one part of formalin- 40 per cent. strength,in one hundred parts of water, that is, a pint of good commercial formaldehyde, also called "formalin," in twelve and one-half gallons of water, was gradually sprinkled over the bed at the 
rate of one gallon per square foot, taking care not to puddle the soil. The bed.was then covered with burlap or sash to hold in the fumes.

Spring treatment leaves the bed wet and cold and it should not be sown for a week after treatment, lest the formalin still in the soil should kill the sprouting seed. Stirring the soil will facilitate the evaporation of the formalin and excessive moisture.

Rate of Seeding. Assuming that clean heavy seed is used,* we wish to call attention to the rate of seeding. The practice of different good growers varies greatly. Four successful growers, each raising a large acreage, gave us their rates of seeding which, calculated to a common basis, are respectively:

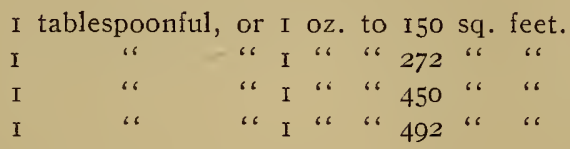

Now one ounce of seed contains approximately 300,000 seeds, of which, assuming a germination of only 75 per cent., 225,000 will sprout and grow.
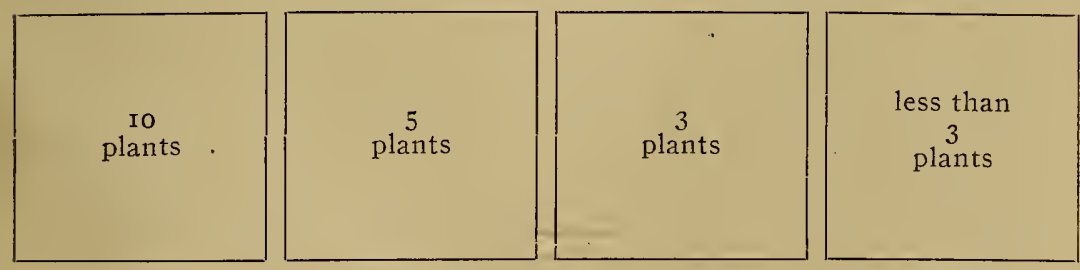

Let the reader imagine the number of seedling plants given above standing in the inch squares and he will see exactly what the above figures mean and understand how thickly the plants will stand on each square inch of his beds, providing 75 per cent. of his seed "comes."

With ten seedlings on a square inch, or even half that number, it is clear that large numbers must die from lack of light, damp-

* The advantage of heavy seed and the method of separating chaff and light seed from it have been explained in the Report of this Station, 1905, p. 334, and in Bull. 96 of the Bureau of Plant Industry. 
ing off, etc., or remain stunted, at least till the overtopping ones are pulled. Such thick crowding, we believe, weakens all the plants, makes them spindling and very hard to pull properly for setting in the field.

An ounce of dry seed is enough to sow on 900 square feet of bed, and this will give a stand of not more than two plants to the square inch.

Sprouted or Dry Seed? It is a very common practice to mix the seed with damp apple-tree "punk," or other suitable material, and leave it in a jar in a warm place until the seed has "cracked" and the sprout appears and then sow the mixture. If a hard, cold storm comes at the time, the grower naturally waits for a better day. Then the sprouts have grown too long and are likely to be broken in sowing, or if not broken they must twist or turn to go down into the soil, thus deforming the root, or a new main root must be formed.

The aim of sprouting the seed is to get a somewhat earlier start for the plant. But it is not likely that an early start of the seed at room temperature helps it much in the end if the tender seedling must be put into the cold soil of the bed. It looks more likely that the plant will have a better chance if the seed germinates at somewhere near the temperature it is to have during its early growth.

Certain it is that young plants taken from a warm to a cool place are set back in growth and often never fully recover.

All tobacco growers know that "hardening off" the plants before setting has to be done very carefully to avoid injury.

It would seem that vastly more injury was likely when seeds, sprouted behind a kitchen stove, are put into soil with a temperature of $40^{\circ}-50^{\circ} \mathrm{F}$., where the exquisitely tender root fiber must "harden off" before it grows further.

The injury is not considered because it cannot be readily seen.

Even if we grant that the preliminary sprouting will give some earlier plants than dry seeding, we believe it is done at the expense of the general thriftiness of the bed, and that to get the crop set in the field very early is rather a doubtful advantage. Cold storms or clear, very cold nights are likely to come and set back the growing crop if it does not kill it. 
Certain it is that the crop will not grow in such cold weather, and when it starts it must grow continuously and fast to give a crop of good quality.

We urge, therefore, that growers make a comparison themselves next spring, sowing sprouted seed and dry seed at the same rate in different parts of the same bed and noting carefully the dates when these beds respectively are ready to "pull" and the comparative vigor of the two.

Watering the Beds. A very successful test of watering the soil from below, subirrigation, was also carried out at Mr. Ackley's.

A line of three-inch glazed tiling was laid from three to five inches deep lengthwise through the middle of the bed. The line had little or no dip and at one end came above the surface outside the bed with an elbow. The tile for 90 square yards of bed cost about $\$ 8.00$. Every other day about forty gallons of water were run into this pipe from a garden hose. No other watering was done except on the surface at the time the seed was sown.

To water an equal area of bed in the usual way while the plants were growing cost $\$ 10.00$ in labor. The cost of subirrigating after the pipe was laid was inconsiderable, say ten minutes' time every other day.

A part of this bed was sterilized with formalin. Here the plants were all healthy. There was some disease in the other part, but the plants grew very rapidly when not diseased and fully as well as in the bed which was watered on the surface by hand.

Where a grower has several beds, we urge the trial of this way of watering on a single bed. If it is as successful generally as it has been with us, it will save labor and expense.

The Use of Tobacco Water on Seed Beds. A decoction of tobacco stems is sometimes used on the seedlings as a fertilizer and also as an insecticide and destroyer of worms in the soil. This should never be done. Dr. Clinton of this Station has proved that the calico disease can be carried in the stems of leaves infected with it, and that tobacco water prepared from such stems may easily infect the plants which are watered with it. $\mathrm{He}$ has no evidence to show that this infection passes from stems plowed into the soil to the young plants. He has been only 
able to induce the trouble by infection through the leaf or the growing part of the stalk.

Ventilation of the Beds. Proper airing of the beds is essential to protect the seedlings from "damping off" and other fungous diseases. It is an art which cannot be taught except by experience with the bed itself. When the air of the bed is nearly saturated and warm, trouble is at hand, just as when the air of the barn full of curing tobacco gets into the same state. And the remedy is the same in both cases, viz., circulation of air to carry off the moisture, even if this causes a loss of heat from the soil, the bed or the barn.

"Calico." The experiments of the Station botanist, Dr. Clinton, so far indicate that most of the "calico". on leaves of commercial value in the field traces back to the seed bed or to infection of the seedlings at the time of transplanting. To explain this more clearly, it should be stated that "calico" is a disease that is very easily transmitted by handling a healthy plant after handling a "calicoed" plant, especially if any of the juices from the "calicoed" plant are on the hands. This juice is only effective on the immature or growing leaves. That is, one can touch with it a fully grown leaf at the base of a tobacco plant and it will not "calico," but the young leaves above will become "calicoed" though not even touched at this time. From this it can be seen that if there are any "calicoed" plants in the seed bed the handling of these while transplanting is likely to greatly spread the "calico" to otherwise healthy plants. This explains why sometimes in the field one finds every other plant "calicoed" for quite a distance in the row. The man who set these either got the juice from a "calicoed" plant on his hands or else got a bunch of plants which had come in contact with "calicoed" plants, while the man who set the alternate sound plants had not these conditions.

Unfortunately "calico" cannot usually be recognized in the plants while in the seed bed. Occasionally before the final setting such plants are found. Whenever they are found, they and the surrounding plants should be pulled out, and the other plants should not be touched until the hands have been washed thoroughly with soap and water. 
So far, the only known methods of lessening "calico" in the seed bed are avoiding the use of tobacco water, as noted before, and the probable good resulting from steam sterilization. Some growers have believed that the careless use of fertilizers on the growing seedlings produced "calico," but if so, this has not yet been proved by experimentation.

The subject of "calico" will be further discussed in the forthcoming report of the Station botanist.

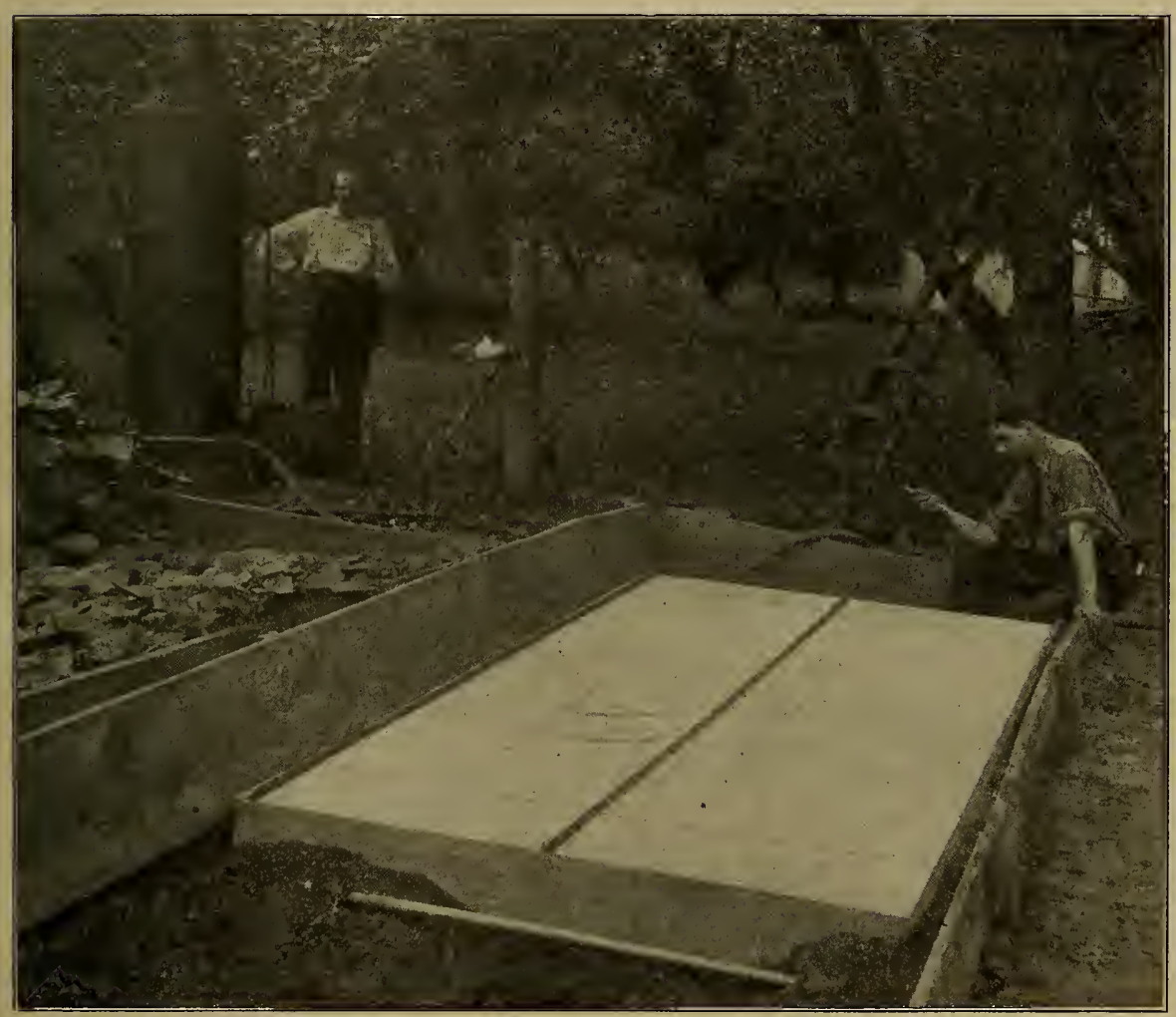

SOIL STERILIZER READY FOR STEAMING. 



\section{University of Connecticut}

Libraries

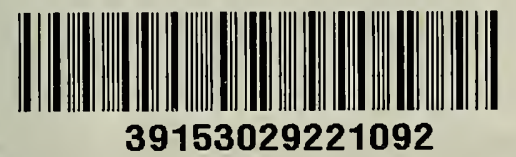


